\title{
Dinotrema cavernicola sp. n. (Hymenoptera, Braconidae, Alysiinae), a new species of the genus Dinotrema Foerster from caves of Spain
}

\author{
Francisco Javier Peris-Felipo', Sergey A. Belokobylskij², \\ Cornelis van Achterberg ${ }^{3}$, Toni Pérez-Fernández ${ }^{4}$
}

I Bleichestrasse 15, CH-4058 Basel, Switzerland 2 Zoological Institute Russian Academy of Sciences, St. Petersburg, 199034, Russia; Museum and Institute of Zoology Polish Academy of Sciences, Wilcza 64, Warszawa 00-679, Poland 3 Naturalis Biodiversity Center, P.O. Box 9517, 2300 RA Leiden, The Netherlands 4 Grupo de Espeleología de Villacarrillo (GEV), Plaza 28 de Febrero, 5-1 ${ }^{\circ}-2^{\circ}, 23300$ Villacarrillo, Jaén, Spain

Corresponding author: Francisco Javier Peris-Felipo (Francisco.peris@uv.es)

Academic editor: G. Broad | Received 17 September 2014 | Accepted 23 November 2014 | Published 22 December 2014

http://zoobank.org/27CF2119-E744-4B4F-B5CB-9F9DDD76D233

Citation: Peris-Felipo FJ, Belokobylskij SA, van Achterberg C, Pérez-Fernández T (2014) Dinotrema cavernicola sp. n. (Hymenoptera, Braconidae, Alysiinae), a new species of the genus Dinotrema Foerster from caves of Spain. Journal of Hymenoptera Research 41: 47-56. doi: 10.3897/JHR.41.8606

\begin{abstract}
Dinotrema cavernicola sp. n. was collected in two caves in Spain. This is the first Dinotrema species known to occur in caves. This new species is described and compared to D. affine (Fischer, 1973) and D. collybiae Munk \& Peris-Felipo, 2014, species sharing a mid-longitudinal carina on the propodeum.
\end{abstract}

\section{Keywords}

Alysiinae, Dinotrema, taxonomy, new species, caves, Diptera

\section{Introduction}

Braconidae is the second largest family of Hymenoptera belonging to the superfamily Ichneumonoidea and with nearly 20,000 valid species around the world (Yu et al. 2012). Nearly all species of Braconidae are primary parasitoids of predominantly immature stages of Lepidoptera, Coleoptera and Diptera (Sharkey 1993). 
The Alysiinae is a conspicuously diverse subfamily within the Braconidae (Dolphin and Quicke 2001) with 2,000 described species (Yu et al. 2012) separated in two large and polymorphic tribes Alysiini and Dacnusini (Shenefelt 1974). Species of Alysiini are parasitoids of a wide variety of cyclorrhaphous Diptera, mainly in humid habitats and ephemeral substrata (Wharton 2002). In contrast, Dacnusini are almost exclusively specialised on leaf- and stem-miner hosts, predominantly of the families Agromyzidae, Ephydridae and Chloropidae (Griffiths 1964, Wharton 2002).

Dinotrema Foerster, 1862 is one of the largest genera within the tribe Alysiini (van Achterberg 1988). It comprises many dozens of species described from the Palaearctic Region and mainly from Western Europe (Fischer 1972; van Achterberg 1988; Tobias 2003, 2004a, 2004b, 2006), but numerous Palaearctic species remain as yet unknown. Increasing our knowledge of this genus, several papers have been published by the two first authors (Peris-Felipo and Belokobylskij 2013; Peris-Felipo et al. 2013a, 2013b, 2013c, 2013d, 2014) and a monograph with a revision of the Western Palaearctic Dinotrema species will be published soon (Peris-Felipo et al. 2014). An arrangement of Dinotrema species in morphological groups was suggested by Fischer (1972) and later, on the basis of more diverse material, further developed by Tobias (2003, 2004a, 2006).

We describe in this paper Dinotrema cavernicola sp. n., and include it in the group of Dinotrema with a complete median longitudinal carina of the propodeum. This is the first record of a Dinotrema species collected in caves.

\section{Materials and methods}

The speleology group of Villacarrillo (Grupo de Espeleología de Villacarillo - GEV) has been conducting intensive fieldwork in caves of Jaén Province (Spain) (Fig. 1). From 2001 up to now many caves have been studied, but in just two caves ("Sistema de la Murcielaguina" and "Sima de la Colada") some braconids were captured.

The "Sistema de la Murcielaguina" is located in Cerro de Hornos (38 $12^{\prime} 59.35^{\prime \prime N}$, $\left.002^{\circ} 42^{\prime} 37.13^{\prime \prime W}\right)$ at an altitude of $1085 \mathrm{~m}$. The maximum depth of the cave system is $80 \mathrm{~m}$ and is more than 4,000 $\mathrm{m}$ long (Fig. 2).

The "Sima de la Colada" is located in La Hoya de Herrera $\left(38^{\circ} 11^{\prime} 11.13^{\prime} \mathrm{N}\right.$, $\left.002^{\circ} 46^{\prime} 45.83^{\prime \prime W}\right)$ at an altitude of $864 \mathrm{~m}$. The maximum depth of the cave is $65 \mathrm{~m}$ and the cave is $352 \mathrm{~m}$ long (Fig. 3).

Both caves are located in the Natural Park and Biosphere reserve of Sierras de Cazorla, Segura and las Villas. Part of it is covered with Mediterranean forest containing Pinus, Quercus, Cistus, Rosmarinus and Thymus species, among others. The climate is warm temperate with moderate temperatures throughout the year $\left(12-18{ }^{\circ} \mathrm{C}\right)$.

Samples were collected by pit-fall traps. All traps are baited with beer, salt and cheese or sobrassada (sausage). In Murcielaguina, specimens were captured in one trap located at $35 \mathrm{~m}$ depth, in complete darkness and with an average temperatures of $15^{\circ} \mathrm{C}$ and $78 \%$ humidity. In Sima de la Colada, specimens were collected in two traps at $65 \mathrm{~m}$ depth with average an temperature of $18^{\circ} \mathrm{C}$ and $80 \%$ humidity. 


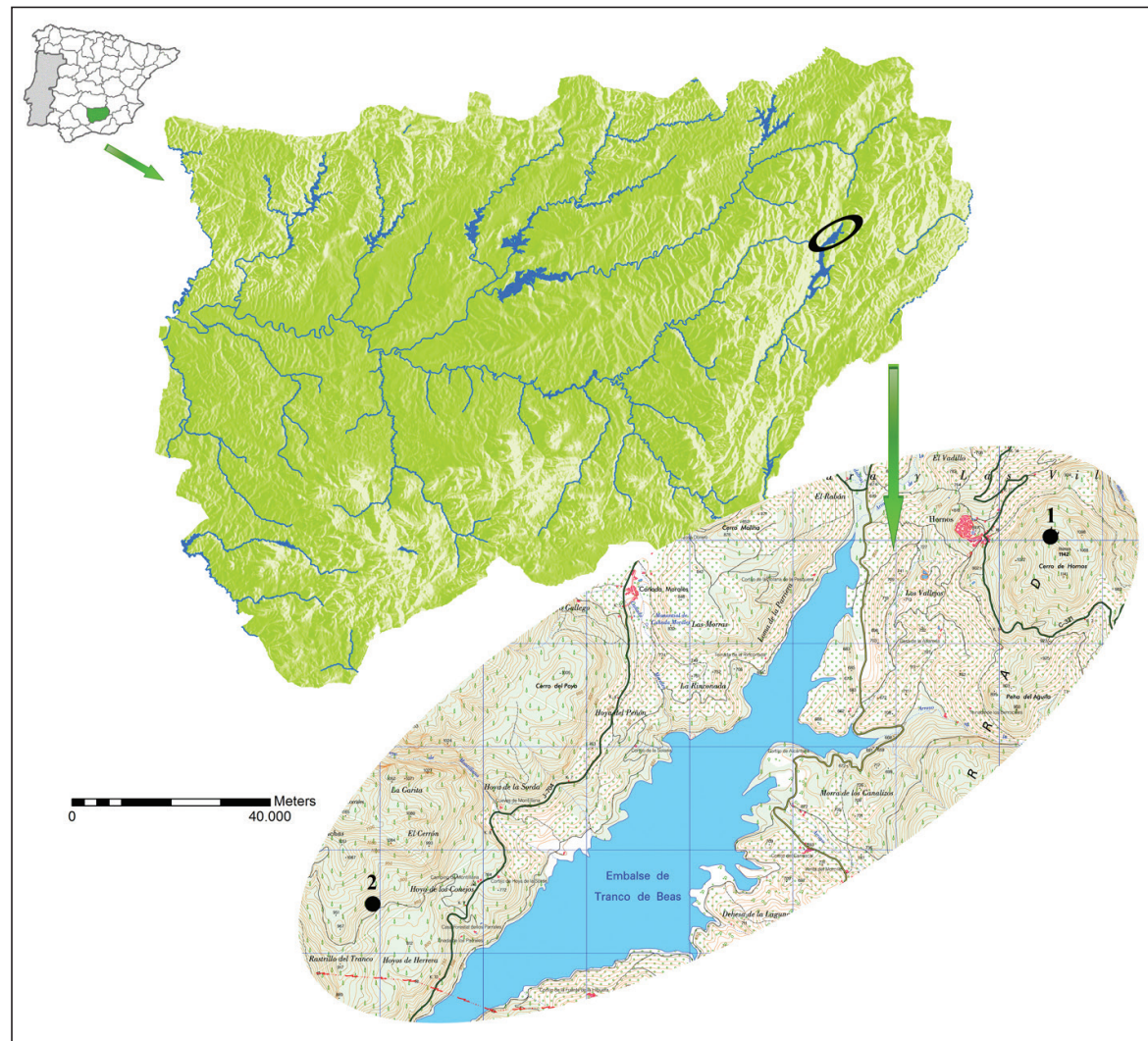

Figure I. Distribution of studied caves. Caves numbers: I Sistema de la Murcielaguina 2 Sima de la Colada.

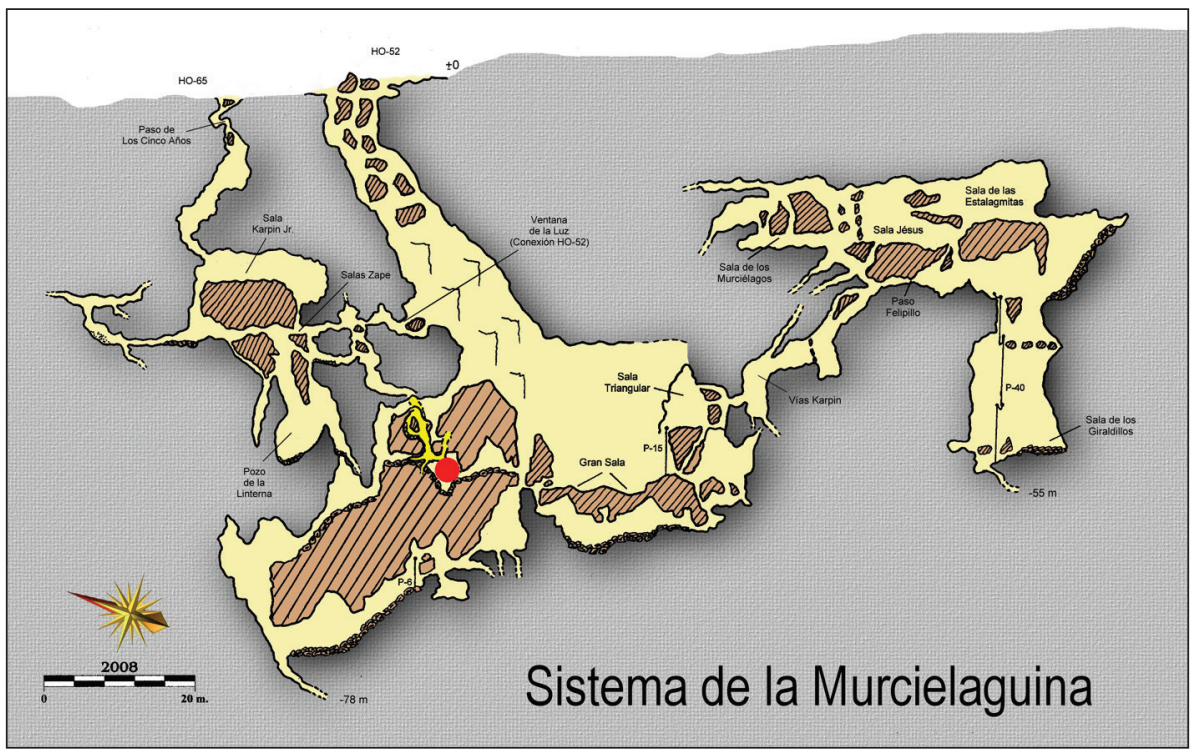

Figure 2. Map of the Sistema de la Murcielaguina with a red dot where specimens were captured. 


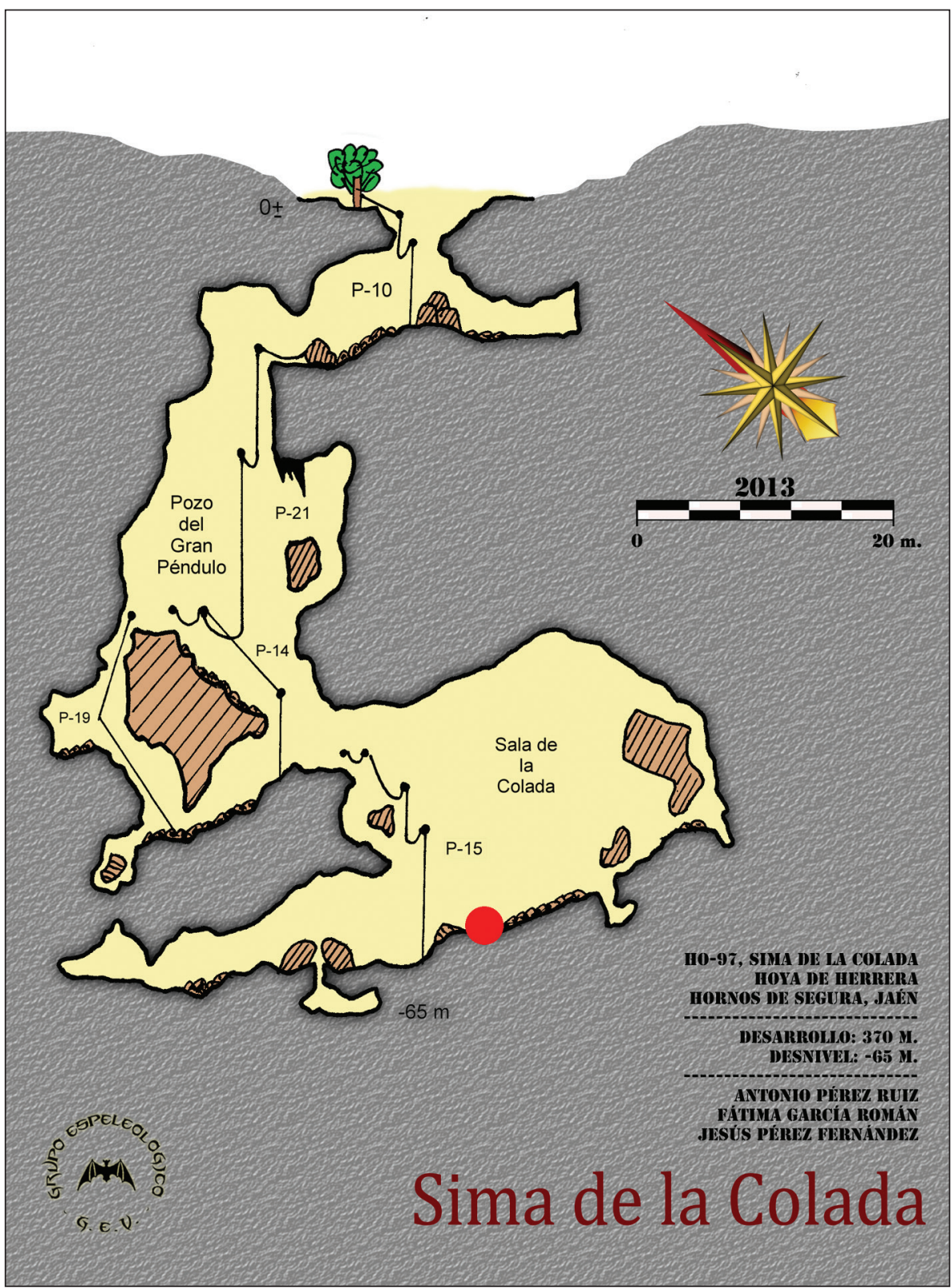

Figure 3. Map of the Sima de la Colada with a red dot where specimens were captured.

Specimens were collected during the summer of 2014 and each cave was visited every two weeks.

For terminology of morphological features and sculpture, measurements and wing venation nomenclature, see Sharkey and Wharton (1997) and HAO (Hymenoptera Anatomy Ontology Portal: http://portal.hymao.org/) (Yoder et al. 2010). To follow 
the identification keys by Peris-Felipo et al. (2014), the following differences in terminology should be kept in mind (terms in Peris-Felipo et al. (2014) second):

Gena: temples.

Anterior tentorial pit: paraclypeal fovea.

Mesoscutal midpit: mesoscutal pit.

Scutoscutellar sulcus: prescutellar depression.

Mesopectus: mesopleuron.

Mesepimeral sulcus: posterior mesopleural furrow.

Marginal cell: radial cell.

Nervulus: vein cu-a.

Second submarginal cell: brachial cell.

Type specimens are deposited in the Entomological Collection at the University of Valencia (Valencia, Spain; ENV), in the Grupo de Espeleología de Villacarillo (Jaén, Spain; GEV), and in the Zoological Institute RAS (St Petersburg, Russia; ZISP).

\section{Taxonomic part}

\section{Dinotrema cavernicola Peris-Felipo, sp. n.}

http://zoobank.org/29ED3F14-03B1-45A4-B499-864B53805AEF

Figs 4-5

Type material. Holotype: female, Spain, Jaén Province, Cerro de Hornos, Sistema de la Murcielaguina, pit-fall trap, - 35 m, 15.vi.2014 (GEV leg.) (ENV). Paratypes: 2 females, same data as holotype (ENV, ZISP); 3 females, Spain, Jaén Province, La Hoya de Herrera, Sima de La Colada, pitfall trap, - 65 m, 17.viii.2014 (GEV leg.) (ENV, GEV, ZISP).

Description. Female.

Head. In dorsal view, 1.7 times as wide as long, 1.3 times as wide as mesoscutum (variation 1.2-1.3 times), smooth, with gena rounded behind eyes. Eye in lateral view 1.5 times as high as wide and 1.2 times as wide as gena. POL about as long as OD; OOL 2.3 times OD. Face 1.5 times as wide as high and covered completely by numerous setae; inner margins of eyes subparallel. Clypeus 2.3 times as wide as high, slightly curved ventrally. Anterior tentorial pit short, not reaching halfway between clypeus and eye. Mandible weakly widened towards apex, 1.6 times as long as its maximum width (variation 1.5-1.6 times). Upper tooth medium sized, wide, shorter than lower and middle tooth. Middle tooth rather small, slightly longer than upper tooth, wide basally and pointed apically. Lower tooth short, wide, rounded. Antenna 21-segmented, 1.1 times as long as body. Scape 2.7 times as long as pedicel. First flagellar segment 4.1 times as long as its apical width (variation 4.1-4.2 times), 1.4 times as long as second segment; second segment 2.5 times as long as its maximum width. Third to twentieth flagellar segments 2.3-2.5 times, and twenty-first segment 2.6 times as long as wide. 

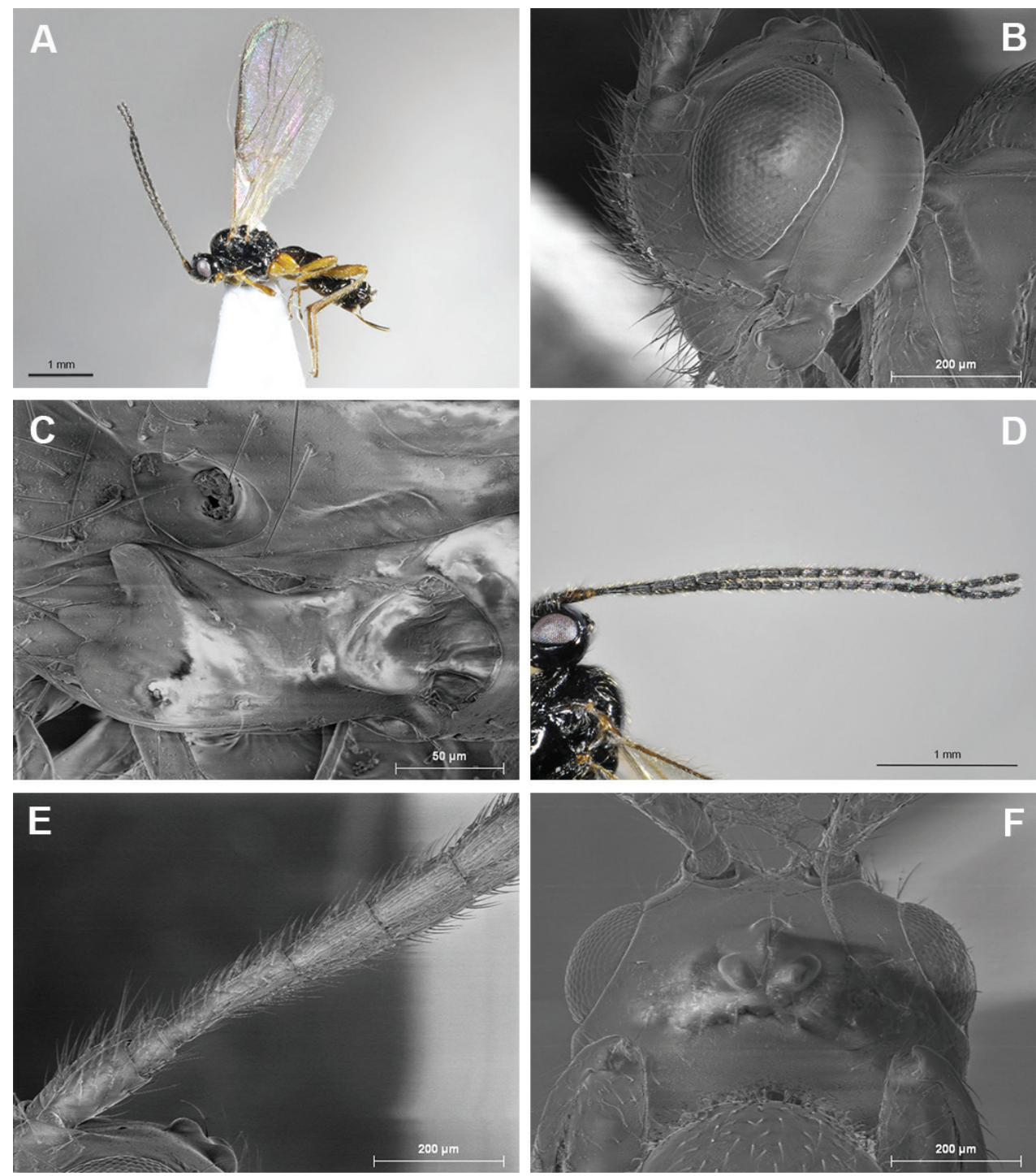

Figure 4. Dinotrema cavernicola sp. n. (female). A Habitus, lateral view B Head, lateral view C Mandible D Antenna E Basal segments of antenna F Head, dorsal view.

Mesosoma. In lateral view, 1.1 times as long as high. Mesoscutum (dorsal view) 0.9 times as long as its maximum width, with numerous setae located on middle part of mesoscutum. Notauli mainly absent on vertical surface of mesoscutum. Mesoscutal midpit present and elongate. Scutoscutellar sulcus smooth, without lateral carinae. Precoxal sulcus present, not reaching anterior and posterior margins of mesopectus. Mesepimeral sulcus smooth. Propodeum mainly smooth, median longitudinal carina complete, with several short transverse carinae crossing median carina but not reaching lateral edge of propodeum. Propodeal spiracles relatively small. 

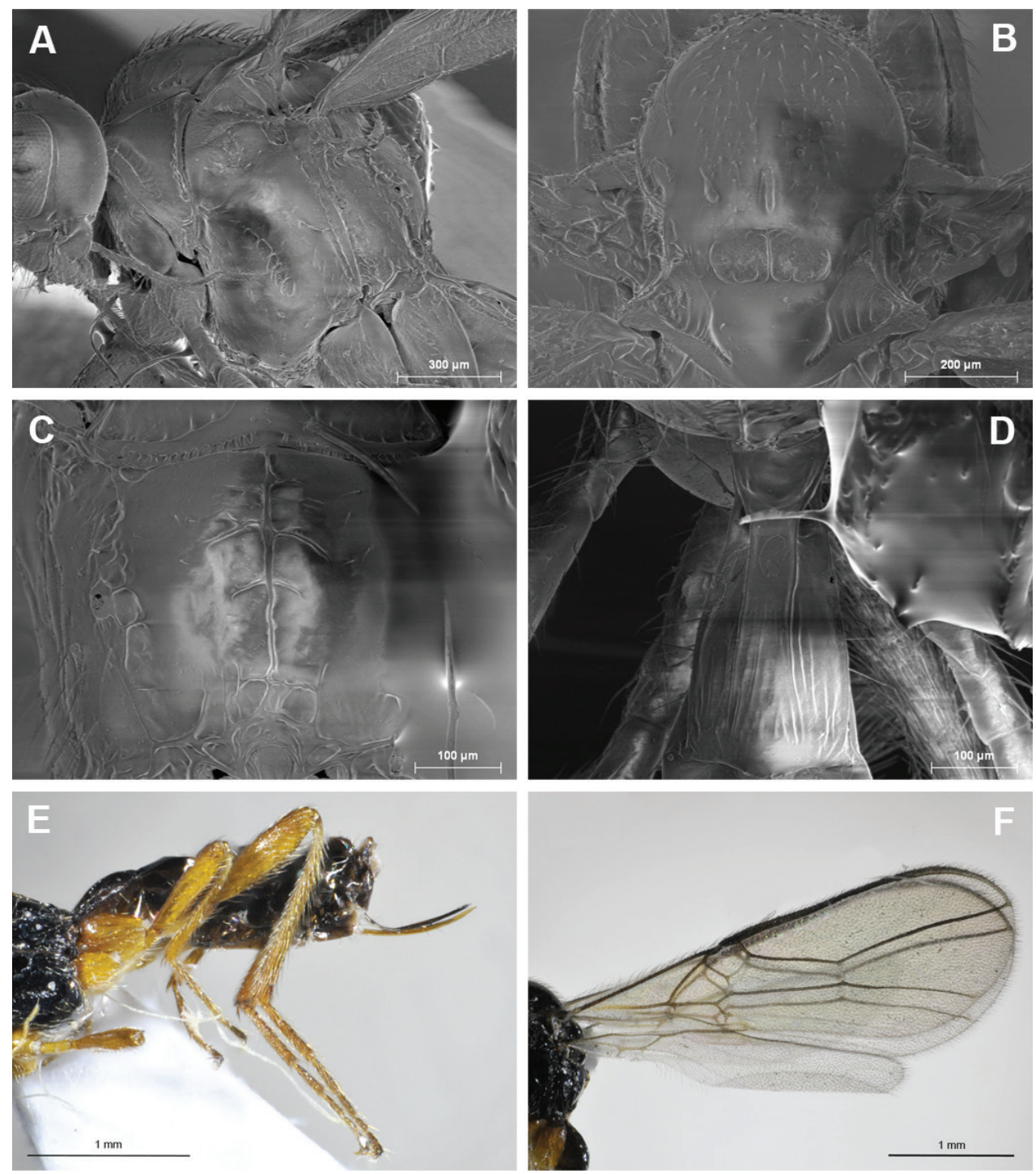

Figure 5. Dinotrema cavernicola sp. n. (female). A Mesosoma, lateral view B Mesonotum, dorsal view C Propodeum, dorsal view D First metasomal tergite E Metasoma, hind leg and ovipositor, lateral view $\mathbf{F}$ Fore and hind wings.

Wings. Length of fore wing 2.4 times its maximum width (variation $2.4-2.5 \mathrm{~mm}$ ). Vein $\mathrm{r} 1$ present and sclerotised. Marginal cell reaching apex of wing, 5.0 times as long as its maximum width. Nervulus distinctly postfurcal. Second submarginal cell closed distally, 2.7 times as long as its maximum width (variation 2.6-2.7 times). Hind wing 5.4 times as long as its maximum width (variation 5.3-5.4 times).

Legs. Hind femur 4.0 times as long as its maximum width (variation 3.9-4.0 times). Hind tibia weakly widened to apex, 9.2 times as long as its maximum subapical 
width, 1.1 times as long as hind tarsus. First segment of hind tarsus 1.7 times as long as second segment.

Metasoma. Long. First tergite weakly widened towards apex, twice as long as its apical width, entirely striate. Ovipositor 1.6 times as long as first tergite, 0.5 times as long as metasoma, 0.9 times as long as hind femur.

Colour. Body, scape, flagellar segments and pterostigma dark brown. Legs, mandible and pedicel yellowish brown. Wings hyaline.

Length. Body $2.7 \mathrm{~mm}$ (variation 2.6-2.8 mm); fore wing $3.4 \mathrm{~mm}$ (variation 3.4$3.5 \mathrm{~mm}$ ).

Male. Unknown.

Etymology. Named "cavernicola" because it inhabits caves.

Comparative diagnosis. According to the key by Peris-Felipo et al. (2014), this new species is similar to D. affine (Fischer, 1973) and D. collybiae Munk \& Peris-Felipo, 2014, both belonging to the species group with a complete median longitudinal carina on the propodeum. Dinotrema cavernicola sp. $n$. differs from D. affine and D. collybiae in having the first flagellar segment 4.1-4.2 times as long as wide (3.5 times in D. affine and 3.2 times in D. collybiae), middle flagellar segments 2.3-2.5 times as long as wide (1.6 times in D. affine and 1.4-1.7 times in D. collybiae), metasoma long (short in D. affine and D. collybiae), POL about as long as OD (1.5 times in D. affine and 1.4 times in D. collybiae); OOL 2.3 times OD (3.0 times in D. affine and 2.0 times in $D$. collybiae), and ovipositor 1.6 times as long as first tergite (0.6 times in D. affine and 1.2 times in D. collybiae).

Remarks. Specimens belonging to the families Phoridae and Heleomyzidae (Diptera) were captured in the same traps as Dinotrema cavernicola sp. n. Among Phoridae, the species Megaselia rufipes (Meigen, 1804) and M. tenebricola Schmitz, 1934 were abundantly captured (determination by Dr. Henry L. Disney, UK). It is interesting M. rufipes was already recorded as a host of some Braconidae taxa, such as Orthostigma pumilum (Nees) (Scott 1920; Lundbeck 1922; Achterberg 1988), Aspilota sp. near nervosa (Schmitz, 1938) and Dinotrema lineola (Thomson) (Mostovski 2001), as well as Platygaster aegeus Walker (Platygastridae) (Morley 1934). Also, Heteromyza atricornis Meigen, 1830 (Heleomyzidae) was abundantly captured during samples (determination by Dr. Miguel Carles-Tolrá, Barcelona, Spain).

\section{Acknowledgements}

We wish to thank the staff of Consejería de Medio Ambiente de la Junta de Andalucía and the Natural Park and Biosphere reserve of Sierras de Cazorla, Segura and Las Villas for their help during this study. Also, we are thankful to the members of GEV (Grupo de Espeleología de Villacarrillo) for their great work in increasing the knowledge of fauna caves over the past 13 years, and this year celebrates the group's 35 th anniversary.

We are very thankful Dr H.L. Disney (UK) and Dr Miguel Carles-Tolrá (Barcelona, Spain) (Heleomyzidae) for determination of the flies. 


\section{References}

Achterberg C van (1988) The genera of the Aspilota-group and some descriptions of fungicolous Alysiini from the Netherlands (Hymenoptera: Braconidae: Alysiinae). Zoologische Verhandelingen 247: 1-88.

Dolphin K, Quicke DLJ (2001) Estimating the global species richness of an incompletely described taxon: an example using parasitoid wasps (Hymenoptera: Braconidae). Biological Journal of the Linnean Society 73: 279-286. doi: 10.1111/j.1095-8312.2001.tb01363.x

Fischer M (1972) Erste Gliederung der palaearktischen Aspilota-Arten (Hymenoptera, Braconidae, Alysiinae). Polskie Pismo Entomology 42(2): 323-459.

Griffiths GCD (1964) The Alysiinae (Hym. Braconidae) parasites of the Agromyzidae (Diptera). Beitraege zur Entomologie 14: 823-914.

Lundbeck W (1922) Diptera Danica, part IV, Pipunculidae, Phoridae. Wesley, London, 1-455.

Mostovski MB (2001) New records of Megaselia (Dipt., Phoridae) parasitized by Alysiinae (Hymenopt., Braconidae). Entomologist's Monthly Magazine 137: 210.

Peris-Felipo FJ, Belokobylskij S (2013) Dinotrema jimenezi sp. n., a new species of the genus Dinotrema (Hymenoptera: Braconidae: Alysiinae) with only basomedially sculptured propodeum from Spain. Biologia 68(5): 979-982. doi: 10.2478/s11756-013-0239-6

Peris-Felipo FJ, Belokobylskij S, Jiménez-Peydró R (2013a) Six new Dinotrema species (Hymenoptera, Braconidae) from Spain, with prescutellar pit and medially sculptured propodeum. Zootaxa 3694(6): 545-564. doi: 10.11646/zootaxa.3694.6.3

Peris-Felipo FJ, Belokobylskij S, Jiménez-Peydró R (2013b) New Spanish Dinotrema species with propodeal areola or mainly sculptured propodeum (Hymenoptera, Braconidae, Alysiinae). ZooKeys 297: 43-70. doi: 10.3897/zookeys.297.5228

Peris-Felipo FJ, Belokobylskij S, Jiménez-Peydró R (2013c) Dinotrema vitobiasi sp. n., a new Spanish species of the genus Dinotrema Foerster with only basomedially sculptured propodeum (Hymenoptera, Braconidae, Alysiinae). Zoosystematica Rossica 22(1): 87-92.

Peris-Felipo FJ, Fischer M, Jiménez-Peydró R (2013d) Five new Dinotrema species with mesoscutal pit and medially sculptured propodeum from Spain (Hymenoptera, Braconidae, Alysiinae). Bulletin of Insectology 66(1): 59-71.

Peris-Felipo FJ, Belokobylskij S, Jiménez-Peydró R (2014) Revision of the Western Palaearctic species of the genus Dinotrema Foerrster, 1862 (Hymenoptera, Braconidae, Alysiinae). Zootaxa 3885(1): 001-483.

Scott H (1920) Notes on the parasitic staphylinid Aleochara algarum Fauvel, and its host, the phycodromid flies; a case of supposed parasitism in the genus Homalota. Entomologist's Monthly Magazine 56: 148-57.

Sharkey MJ (1993) Family Braconidae. In: Goulet H, Huber JT (Eds) Hymenoptera of the World: An Identification Guide to Families. Agriculture Canada (Canada), 362-395.

Sharkey MJ, Wharton RA (1997) Morphology and terminology. In: Wharton RA, Marsh PM, Sharkey MJ (Eds) Manual of the New World Genera of the Family Braconidae (Hymenoptera). International Society Hymenopterists, Washington D.C., 19-37.

Shenefelt RD (1974) Pars 11. Braconidae 7. Alysiinae. In: Van der Vecht J, Shenefelt RD (Eds) Hymenopterorum Catalogus (nova edition). Dr. W. Junk BV, The Hague, 937-1113. 
Tobias VI (2003) Species of the genus Dinotrema Foerster, 1862 (Hymenoptera, Braconidae, Alysiinae) without prescutellar pit and with smooth or only medially sculptured propodeum from Russia and adjacent territories. Entomological Review 83(3): 279-294.

Tobias VI (2004a) Species of the genus Dinotrema Foerster (Hymenoptera, Braconidae, Alysiinae) without prescutellar pit and with a widely sculptured propodeum and short mandibles from Russia and neighboring territories. Entomological Review 84(2): 216-232.

Tobias VI (2004b) Two new species of the braconid genus Dinotrema Foerster (Hymenoptera, Braconidae, Alysiinae) without prescutellar pit. Entomological Review 84(6): 673-676.

Tobias VI (2006) Palaearctic species of the genus Dinotrema Foerster (Hymenoptera, Braconidae, Alysiinae) with prescutellar pit and long ovipositor. Entomological Review 86(3): 324-336. doi: $10.1134 / S 0013873806030092$

Yoder MJ, Mikó I, Seltmann KC, Bertone MA, Deans AR (2010) A Gross Anatomy Ontology for Hymenoptera. PLoS ONE 5(12): e15991. doi: 10.1371/journal.pone.0015991

Yu DS, Achterberg C van, Horstman K (2012) Taxapad 2012, Ichneumonoidea 2011. Database on flash-drive. Ottawa, Ontario, Canada. 